Article

\title{
Extraction, Quantification, and Cytokine Inhibitory Response of Bakuchiol in Psoralea coryfolia Linn.
}

\author{
Deepak Khuranna ${ }^{1}$, Sanchit Sharma ${ }^{1}$, Showkat Rasool Mir ${ }^{1}$, Mohd Aqil ${ }^{2}$, Ajaz Ahmad ${ }^{3}$, \\ Muneeb U Rehman ${ }^{3}$, Parvaiz Ahmad ${ }^{4}{ }^{\circledR}$, Mona S. Alwahibi ${ }^{4}$, Mohamed Soliman Elshikh ${ }^{4}$ and \\ Mohd Mujeeb ${ }^{1, *}$ \\ 1 Department of Pharmacognosy and Phytochemistry, School of Pharmaceutical Education and Research, \\ Jamia Hamdard, New Delhi 110062, India; 111.khurana@gmail.com (D.K.); \\ sanchitsharma4@gmail.com (S.S.); srmir@jamiahamdard.ac.in (S.R.M.) \\ 2 Department of Pharmaceutics, School of Pharmaceutical Education and Research, Jamia Hamdard, \\ New Delhi 110062, India; maqil@jamiahamdard.ac.in \\ 3 Department of Clinical Pharmacy, College of Pharmacy, King Saud University, Riyadh 11451, Saudi Arabia; \\ aajaz@ksu.edu.sa (A.A.); mrehman1@ksu.edu.sa (M.U.R.) \\ 4 Department of Botany and Microbiology, College of Science, King Saud University, \\ Riyadh 11451, Saudi Arabia; parvaizbot@yahoo.com (P.A.); malwahibi@ksu.edu.sa (M.S.A.); \\ melshikh@ksu.edu.sa (M.S.E.) \\ * Correspondence: mmujeeb@jamiahamdard.ac.in
}

Received: 18 August 2020; Accepted: 31 August 2020; Published: 11 September 2020

check for updates

\begin{abstract}
Background: The present investigation studies the optimization of extraction, quantification, and cytokine inhibitory effects bakuchiol (BKL) in Psoralea coryfolia Linn. (2) Methods: The seeds of Psoralea coryfolia cleaned, dried, and powdered. Different separation methods maceration, reflux, Soxhlet, and ultrasonic assisted extraction (UAE) were employed for the isolation of BKL by five pure solvents. The quantity of BKL was measured by high-performance liquid chromatography (HPLC) method to determine the highest yield percentage. The effect of optimized BKL was then tested in an animal model of sepsis induced by lipopolysaccharides (LPS). (3) Results: The UAE method was found to be the best among tested separation methods and yielded highest percentage of BKL in petroleum ether extract. Septic rats showed a significant elevation in levels of biochemical markers like AST, ALT, ALP, BIL, SCr, and BUN in plasma. Proinflammatory cytokines (TNF- $\alpha$ and IL-1) levels were also increased in LPS-induced animals. BKL has been found to significantly reverse these elevated levels as compared to the LPS-induced animals. (4) Conclusion: The present results suggest that BKL has positive effects when administered in animals with pathogenic shock by decreasing the circulating levels of biomarkers. Further studies are necessary to explore the clinical implications of such findings.
\end{abstract}

Keywords: Psoralea coryfolia; extraction; bakuchiol; HPLC; LPS; cytokine

\section{Introduction}

The fabaceae plant, Psoralea corylifolia L., is a medicinal plant widely distributed in India, China, and Southeastern Asian countries [1,2]. Dried seeds of P. corylifolia L. are a rich source of flavonoids and meroterpenes such as bakuchiol, psoralen, etc., possessing a wide range of pharmacological activities (antimicrobial, antibacterial, anti-inflammatory, cytotoxic, and inhibiting nitric oxide (NO) production) [3,4]. It grows throughout the plains of India, especially in the semiarid regions of Rajasthan and eastern districts of Punjab, adjoining Uttar Pradesh. It is also found throughout India in Himalayas, Dehradun, and Karnataka [1,5]. This plant is also widely distributed in the tropical and subtropical regions of the world, especially China and southern Africa [2]. The active fraction isolated from 
fruits, seeds, and roots possesses antibacterial, anti-oxidative, and immunomodulatory properties [6]. Major chemical constituents are psoralen, bakuchiol, bakuchicin, and minor phytoconstituents angelicin, psoralidin, bavachromanol, 7-O-methylbavachin, psoralidin oxide [2]. Seed oil contains glycerides of oleic acid, steric acid, palmitic acid, myristic acid, myristoleic acid, lenoleic acid, along with stigmasterol and b-sitosterol [7].

Lipopolysaccharide (LPS) is the principal constituent of cell walls of Gram-negative bacteria and can induce acute inflammatory response by triggering the release of a large number of inflammatory cytokines in different types of cells [8]. LPS is commonly recognized as being potent macrophage and monocyte activator [9]. LPS has been widely used to study inflammation because of the abundance of inflammatory effects it provides by various signaling pathways [10]. LPS is known to induce the production of cytokines such as tumor necrosis factor alpha (TNF- $\alpha$ ) and interleukins. The cytokines are the primary response against pathogen [11]. Bakuchiol (BKL) (Figure 1), one of the major constituent of $P$. corylifolia, has been shown to possess a prominent cytotoxic effect. BKL, a monoterpene prevented mitochondrial lipid peroxidation. BKL has been known for a long time and is widely used in cosmetics [12]. The water-soluble extract containing BKL has been found to possess hepatoprotective activity $[13,14]$. BKL has been reported in preventing or treating a woman suffering osteoporosis [15]. BKL has been shown to possess anti-inflammatory activities [16]. BKL showed broad antioxidant activities in rat liver microsomes and mitochondria. BKL prevented mitochondrial lipid peroxidation and also possesses DNA polymerase inhibitory activity [17]. Due to its potent antioxidant and anti-inflammatory potential, the current study aimed to investigate the effect of extraction, quantification, and cytokine (TNF- $\alpha$ and IL-1) inhibitory response of BKL in Psoralea coryfolia Linn.<smiles>C=C[C@@](C)(/C=C/c1ccc(O)cc1)CCC=C(C)C</smiles>

Figure 1. Chemical structure of bakuchiol.

\section{Materials and Methods}

\subsection{Plant Collection}

The P. corylifolia seeds were purchased from the local market in New Delhi and were authenticated by a taxonomist at Jamia Hamdard. The powdered seeds of $P$. corylifolia $L$. were subjected to various methods of extraction. Extraction and comparison of extractive methods were performed with respect to BKL content.

\subsection{Extraction of Bakuchiol}

\subsubsection{Maceration Extraction}

About $10 \mathrm{~g}$ of powdered seeds were extracted using different solvents (ethanol, methanol, acetone, petroleum ether, and dichloromethane), $(70 \mathrm{~mL}$; Drug: Solvent ratio- $-1: 7 \times 2$ times) by maceration for $7 \mathrm{~d}$ each and the process was repeated for another $7 \mathrm{~d}$, filtrates were combined and then extracts were evaporated to dryness using rotary vacuum evaporator (Rotary evaporator HS-2005V) at $40{ }^{\circ} \mathrm{C}$ under inert atmosphere to obtain brown-colored sticky mass. The extract was weighed and was subjected to further quantification. 


\subsubsection{Reflux Extraction}

The solvent $(50 \mathrm{~mL})$ and P. corylifolia L. seed powder $(10 \mathrm{~g})$ were added to the flask $(250 \mathrm{~mL})$, and the mixture was refluxed for $40 \mathrm{~min}$ using different solvents (ethanol, methanol, acetone, petroleum ether, and dichloromethane) in drug: solvent ratio (1:7). The solution was filtered and the extraction process was repeated two more times with fresh solvents. The filtrates were combined, and the solvent was evaporated using rotary vacuum evaporator (Rotary evaporator HS-2005V) to obtain a dried brownish sticky extract. The extract was weighed and subjected to further quantification.

\subsubsection{Soxhlet Extraction}

The coarse powder (10/44 mesh size) of dried seeds of P. corylifolia L. (10 g) was extracted with different solvents (ethanol, methanol, acetone, petroleum ether, and dichloromethane) in drug: solvent ratio of 1:12 by hot solvent extraction for $6 \mathrm{~h}$ each using Soxhlet apparatus. The different extracts were concentrated under reduced pressure in a rotary vacuum evaporator (Rotary evaporator HS-2005V) at $40^{\circ} \mathrm{C}$ to obtain brownish colored sticky mass. The extract was evaporated to dryness to get brownish extract, which was weighed and subjected to further quantification.

\subsubsection{Ultrasonic Assisted Extraction}

The coarse powder of P. corylifolia L. (10 g) was extracted with different solvents (ethanol, methanol, acetone, petroleum ether, and dichloromethane) in drug: solvent ratio of 1:14 by ultra-sonication method for $45 \mathrm{~min}$ with input power of $220 \mathrm{~V}$ and heating power of $550 \mathrm{~W}$, equipped with time and temperature controller. The extracts obtained were concentrated under reduced pressure to obtain brownish colored sticky mass. The extract was evaporated to dryness to get brownish extract, which was weighed and subjected to further quantification.

\subsection{Quantitative Analysis of Bakuchiol by High-Performance Liquid Chromatography (HPLC)}

BKL content in different extraction methods was determined through high-performance liquid chromatography (HPLC), the details of which are given below.

\subsubsection{Instrument Specification}

HPLC Binary System (SHIMADZU, Koyoto, Japan) comprising LC-10AT VP pumps, a single wave length programmable UV-visible detector, and a system controller. Samples were injected by using a rheodyne injector fitted with a $20-\mu \mathrm{L}$ fixed loop. Standard and sample solutions were filtered through $0.2-\mu \mathrm{m}$ syringe filter before injection. The separation was achieved by using column with $250 \times 4.6 \mathrm{~mm}$, particle size $5 \mu \mathrm{m}$, Lichrospher $\mathrm{C}_{18}$ reverse phase column (Merck, Darmstadt, Germany). The targeted compounds were eluted using mobile phase as acetonitrile $(\mathrm{ACN})$ or methanol and water gradient from $36-100 \%$ ACN over a period of $20 \mathrm{~min}$, followed by $100 \% \mathrm{ACN}$ for three minutes. The detection was done at $262 \mathrm{~nm}$. The detailed HPLC conditions used are set forth in the table mentioned below.

\subsubsection{HPLC Conditions for Quantification of Bakuchiol}

$\begin{array}{ll}\text { Column } & \text { Merck C18 RP (4.6 mm } \times 250 \mathrm{~mm}, 5 \mu \mathrm{m}) \\ & 0-8 \mathrm{~min} 36 \% \mathrm{ACN} / \text { Water } \\ \text { Gradient } & 8-20 \mathrm{~min} 36 \% \mathrm{ACN} / \text { Water to } 100 \% \mathrm{ACN} \\ & 20-23 \mathrm{~min} 100 \% \mathrm{ACN} \\ & 23-28 \mathrm{~min} 36 \% \mathrm{ACN} / \text { Water } \\ \text { Flow rate } & 1 \mathrm{~mL} / \mathrm{min} \\ \text { Detection } & 262 \mathrm{~nm} \\ \text { Temperature } & 35^{\circ} \mathrm{C}\end{array}$




\subsubsection{Preparation of Calibration Curve and Quantification of Bakuchiol}

Stock solution of BKL (INDOFINE, Hillsborough, NJ, USA) was prepared in methanol from the standard substance: concentration $1 \mathrm{mg} / \mathrm{mL}$. Then working solutions of 9.375, 18.75, 37.5, 75, and $150 \mu \mathrm{g} / \mathrm{mL}$ were prepared in HPLC grade methanol and further diluted to get required concentration, stored at $-20^{\circ} \mathrm{C}$ and brought to room temperature before use. Each standard solution was filtered through $0.2 \mu \mathrm{m}$-membrane filter and then subjected to HPLC analysis to obtain a peak height at a static retention time for each standard solution. Calibration plot was then made for concentration $\left(\mu \mathrm{gL}^{-1}\right)$ versus peak area. The plot was further used to determine concentration of BKL in test samples. $10 \mathrm{mg}$ of the different extract of seeds of P. corylifolia L. was weighed and dissolved in HPLC grade methanol to make final concentration of $200 \mu \mathrm{g} \mathrm{mL}^{-1}$. The solution was then filtered through $0.2-\mu \mathrm{m}$ membrane filter and $20 \mu \mathrm{L}$ of the resulting solution was subjected for HPLC analysis and the concentration of BKL in the extracts was then calculated based on the equations for the calibration curves.

\subsection{Cytokine Inhibitory Effects}

Animal Model of Inflammation and Treatment

Wistar rats were obtained from the animal care facility of Jamia Hamdard, New Delhi, India (IAEC No: Project: 903). The animals were kept under optimal environmental conditions $\left(25 \pm 2{ }^{\circ} \mathrm{C}\right.$, and $12 \mathrm{~h} \mathrm{light/dark} \mathrm{cycle)} \mathrm{and} \mathrm{were} \mathrm{given} \mathrm{free} \mathrm{access} \mathrm{to} \mathrm{standard} \mathrm{rat} \mathrm{pellet} \mathrm{food} \mathrm{and} \mathrm{water.} \mathrm{The} \mathrm{animal}$ care guidelines for the care and use of laboratory animals were used to handle the animals. The animals were divided into five groups and 6 rats were allotted to each group $(n=6)$. Animals in Group I served as control. Animals in Group II served as disease control and were given LPS (10 mg/kg, i.p.). Group III and IV received BCL at 30 and $60 \mathrm{mg} / \mathrm{kg}$, p.o., respectively, for $7 \mathrm{~d}$ prior to the systemic inflammation induced by LPS $(10 \mathrm{mg} / \mathrm{kg}$, i.p.). The animals were anesthetized under isoflurane $6 \mathrm{~h}$ after LPS challenge. The blood samples were collected in heparinized tubes and plasma was separated and stored at $-80^{\circ} \mathrm{C}$ for further analysis. The relevant biochemical estimation like aspartate aminotransferase (AST), alanine aminotransferase (ALT), alkaline phosphatase (ALP), bilirubin (BIL), serum creatinine (Scr), blood urea nitrogen (BUN), nitric oxide (NO) and cytokine levels (TNF- $\alpha$ and IL-1) were determined using ELISA according to manufacturer details (BioVision, Milpitas, CA, USA).

\subsection{Statistical Analysis}

The one-way ANOVA followed by Dunnett's post hoc testing was used to estimate the difference in biochemical parameters and cytokine levels among the groups.

\section{Results and Discussion}

Bakuchiol was extracted using different techniques like (a) maceration, (b) reflux extraction, (c) Soxhlet extraction, (d) ultrasonic assisted extraction, with different solvents to select the best method with highest extraction of BKL and the best solvent in which higher yield of BKL is present. The extracts obtained were weighed and were subjected to quantification using HPLC methods. Extraction of BKL from P. corylifolia L. dried seeds was carried out using five different techniques and with different solvents (with different polarities) to select the best technique and best solvent for highest yield of BKL from P. corylifolia L (Table 1). Ultrasonication assisted extraction (UAE) technique was found out to be the best method for highest extraction of BKL $(6.98 \%, w / w)$ with petroleum ether being the best solvent for its extraction. Whereas BKL content using maceration, reflux, and soxhlet apparatus, were found to be $5.32 \%(w / w) ; 6.01 \%$, and $6.68 \%(w / w)$, respectively, with petroleum ether as the solvent. Clearly, BKL content obtained using ultrasonication assisted extraction was the highest as quantified using HPLC and the time taken with this technique was the lowest, compared to soxhlet apparatus, maceration and Reflux method. This is due to its low temperatures, which decreases the heat loss caused by high temperatures; also prevents vaporization during boiling, and also prevents the preservation of biologically active substances $[18,19]$. Therefore, ultrasonication assisted extraction 
(UAE) was selected further for BKL extraction as it gives the highest yield of BKL and it requires less time being highly efficient as compared to the other extraction methods (RT $24.5 \mathrm{~min}$ ). Petroleum ether was selected as the best solvent for BKL extraction on the basis of a comparative study with other solvents (such as methanol, acetone, dichloromethane, and ethanol). In the present study, the extraction equipment, extraction time, and drug solvent ratio was kept as constant for all the solvents. It was found that BKL content was found to be the highest in petroleum ether extracts, which makes it a favorable choice of solvent for extraction of BKL (Figure 2).

In septic rats, lethargy, bending gait, and piloerection were observed soon after LPS administration, but animals treated BKL showed either insignificant or none of the above symptoms. The intraperitoneal administration of LPS in rats shows tissue damage confirmed by a significant increase in AST (654.29 \pm 25.78$), \operatorname{ALT}(745.21 \pm 34.87), \operatorname{ALP}(234.54 \pm 11.34)$, and BIL (2.65 \pm 0.45$)$ levels as compared to normal rats (Table 2). The pretreatment of BKL prevented the tissue damage as evident by as a significant $(p<0.5)$ decrease in AST $(403.45 \pm 21.77)$, ALT $(503.65 \pm 31.99)$, ALP $(163.66 \pm 6.77)$, and BIL $(1.96 \pm$ $0.23)$ levels with $(30 \mathrm{mg} / \mathrm{kg}$ dose); and AST (246.87 \pm 19.98$)$, ALT (223.55 \pm 18.94$)$, ALP (109.34 \pm 4.87$)$, and BIL (1.12 \pm 0.18$)$ levels with $(60 \mathrm{mg} / \mathrm{kg}$ dose) respectively, in a dose-dependent manner as compared to the animals received LPS only (Table 2). Also, a decrease in SCr at $30 \mathrm{mg} / \mathrm{kg}(0.48 \pm 0.07 \mathrm{mg} / \mathrm{dL}$ $p<0.05)$ and $(0.43 \pm 0.03 \mathrm{mg} / \mathrm{dL} p<0.05)$ at $60 \mathrm{mg} / \mathrm{kg}$, and BUN $(109.77 \pm 5.76 \mathrm{mg} / \mathrm{dL} p<0.05)$ at $30 \mathrm{mg} / \mathrm{kg}$ and $(74.59 \pm 4.98 \mathrm{mg} / \mathrm{dL} p<0.05)$ at a dose of $60 \mathrm{mg} / \mathrm{kg}$ were observed in BKL treated groups as compared to the animals in LPS group SCr $(0.65 \pm 0.08 \mathrm{mg} / \mathrm{dL})$ and BUN $(165.66 \pm 8.83 \mathrm{mg} / \mathrm{dL})$, respectively. The LPS administration caused increased levels of NO $(107.33 \pm 3.87 \mu \mathrm{M})$, which was significantly reversed in BKL treated animals at a dose-dependent manner $(81.89 \pm 3.18$ and $51.25 \pm$ $2.62 \mu \mathrm{M} p<0.05)$ at a dose of 30 and $60 \mathrm{mg} / \mathrm{kg}$, respectively.

In the present research, LPS caused dysregulation of kidney and liver function of biochemical markers used for the determination of particular organ damage. LPS caused increase in organ function biochemical markers of, AST, ALT, ALP, BIL, SCr, and BUN in plasma of animals. This increase in biochemical indices by LPS has been previously reported [20]. LPS has been proposed to produce $\mathrm{NO}$ and other reactive oxygen species (ROS), which causes peroxidation and cell modifications that further leads to the cell membrane disruption and following release of cell contents [21]. BKL treatment markedly reversed the alterations induced by LPS by ameliorating the levels of AST, ALT, ALP, BIL, SCr, and BUN. LPS causes elevated nitrite levels in LPS administered animals as compared to normal control animals. It is well known that LPS causes a significant increase in the nitrite levels because of over expression of inducible nitric oxide (iNOS) [22,23]. NO produces a potent oxidant peroxynitrite $\left(\mathrm{ONOO}^{-}\right)$by reacting with superoxide anion $\left(\mathrm{O}^{-}\right)$, which increases the lipid peroxidation and causes oxidative damages in different tissues [24]. The BKL treatment was found to have protective effect against LPS-induced damage as apparent by the significant decrease in circulating NO levels. These results were in agreement with the results of Alkharfy and colleagues in 2015, who reported that thymoquinone significantly decreases the plasma levels of nitric oxide and the survival in animal model of sepsis [25]. Administration of LPS to animals produced an acute systemic inflammation established by a significant increase proinflammatory cytokines TNF- $\alpha$ and IL-1 levels as compared to normal control animals. The BKL at 30 and $60 \mathrm{mg} / \mathrm{kg}$ diminishes the plasma TNF- $\alpha$ and IL-1 levels in a dose-dependent manner significantly (Figure 3). Sepsis is distinguished by a proinflammatory systemic reaction that may contribute to extreme sepsis or septic shock [26]. Septic infection is a significant health care concern around the globe, impacting millions of people per year and growing their occurrence annually [27]. Although major improvements over the years in intensive care management, septic shock is often correlated with high mortality rates [28]. Sepsis has been found to evolve when the original, appropriate host reaction to an infection is exacerbated and eventually dysregulated, resulting in difference between pro- and anti-inflammatory responses [29]. Cytokines control a number of inflammatory responses, including the movement of immune cells to the infection site, which is a key step in controlling and avoiding a localized infection from being widespread. Nonetheless, a dysregulated release of cytokines may result in organ dysfunctions [30,31]. 
Table 1. Bakuchiol content in different extracts using different extraction techniques.

\begin{tabular}{|c|c|c|c|c|c|c|c|c|}
\hline \multirow[b]{2}{*}{ Solvents } & \multicolumn{2}{|c|}{ Maceration } & \multicolumn{2}{|c|}{ Reflux } & \multicolumn{2}{|c|}{ Soxhlet } & \multicolumn{2}{|c|}{ UAE } \\
\hline & $\begin{array}{l}\text { \% Yield of } \\
\text { Crude Extract }\end{array}$ & $\begin{array}{c}\% \text { Bakuchiol } \\
(w / w)\end{array}$ & $\begin{array}{l}\text { \% Yield of } \\
\text { Crude Extract }\end{array}$ & $\begin{array}{c}\% \text { Bakuchiol } \\
(w / w)\end{array}$ & $\begin{array}{c}\% \text { Yield } \\
\text { Crude Extract }\end{array}$ & $\begin{array}{c}\% \text { Bakuchiol } \\
\text { Content }(w / w)\end{array}$ & $\begin{array}{c}\text { \% Yield } \\
\text { Crude Extract }\end{array}$ & $\begin{array}{c}\% \text { Bakuchiol } \\
(w / w)\end{array}$ \\
\hline $\mathrm{MeOH}$ & 13.71 & 5.21 & 16.81 & 5.72 & 19.21 & 6.25 & 15.81 & 5.79 \\
\hline $\mathrm{EtOH}$ & 14.20 & 4.84 & 17.09 & 5.79 & 12.40 & 4.10 & 18.60 & 5.79 \\
\hline Pet Ether & 11.22 & 5.32 & 12.43 & 6.01 & 12.92 & 6.68 & 11.51 & 6.98 \\
\hline Acetone & 12.71 & 1.51 & 14.69 & 4.40 & 13.01 & 4.34 & 13.67 & 4.48 \\
\hline DCM & 12.90 & 2.31 & 13.42 & 2.20 & 13.19 & 3.32 & 12.42 & 2.29 \\
\hline
\end{tabular}

(w/w: Weight of crude extract/weight of the final concentration).

Table 2. Effect of bakuchiol pretreatment on plasma markers in lipopolysaccharides (LPS)-induced inflammation.

\begin{tabular}{|c|c|c|c|c|}
\hline Plasma & Control & LPS (10 mg/kg) & BKL $30 \mathrm{mg} / \mathrm{kg}$ + LPS & BKL $60 \mathrm{mg} / \mathrm{kg}$ + LPS \\
\hline AST (U/L) & $78.24 \pm 4.21$ & $654.29 \pm 25.78$ & $403.45 \pm 21.77$ *\# & $246.87 \pm 19.98$ *\# \\
\hline $\operatorname{ALT}(\mathrm{U} / \mathrm{L})$ & $54.55 \pm 3.91$ & $745.21 \pm 34.87$ & $503.65 \pm 31.99$ *\# & $223.55 \pm 18.94$ *\# \\
\hline $\operatorname{ALP}(\mathrm{U} / \mathrm{L})$ & $59.11 \pm 3.34$ & $234.54 \pm 11.34 *$ & $163.66 \pm 6.77^{* \#}$ & $109.34 \pm 4.87$ *\# \\
\hline Bilirubin (mg/dL) & $0.32 \pm 0.01$ & $2.65 \pm 0.45^{*}$ & $1.96 \pm 0.23$ *\# & $1.12 \pm 0.18$ *\# \\
\hline Serum Creatinine (mg/dL) & $0.33 \pm 0.05$ & $0.65 \pm 0.08 *$ & $0.48 \pm 0.07$ *\# & $0.43 \pm 0.03$ *\# \\
\hline $\mathrm{BUN}(\mathrm{mg} / \mathrm{dL})$ & $45.34 \pm 2.06$ & $165.66 \pm 8.83$ * & $109.77 \pm 5.76^{* \#}$ & $74.59 \pm 4.98 * \#$ \\
\hline $\mathrm{NO}(\mu \mathrm{M})$ & $33.21 \pm 1.28$ & $107.33 \pm 3.87$ * & $81.89 \pm 3.18$ *\# & $51.25 \pm 2.62 * \#$ \\
\hline
\end{tabular}

Results are represented as mean \pm SEM of six rats/group. ${ }^{*} p<0.05$ vs. control; ${ }^{\#} p<0.05$ vs. LPS group. 

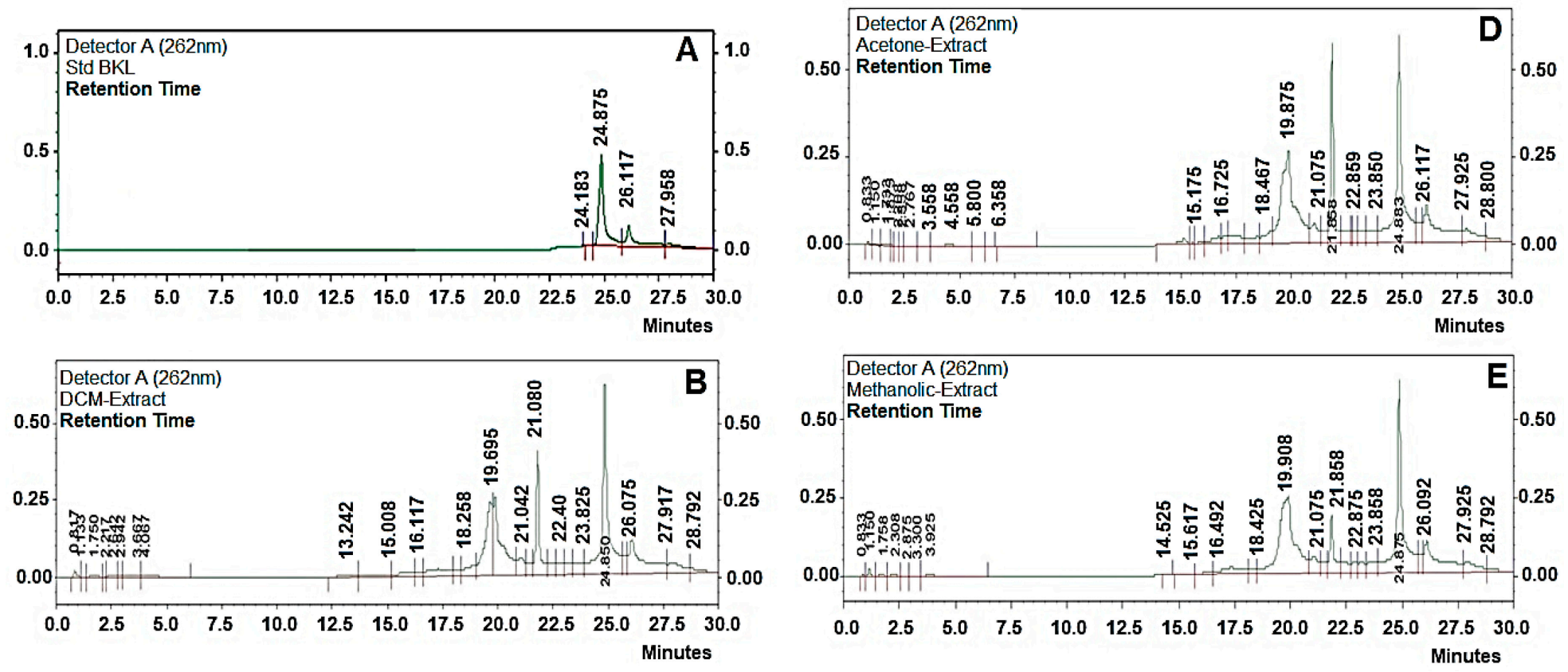

$\begin{array}{lllllllllllllll}0.0 & 2.5 & 5.0 & 7.5 & 10.0 & 12.5 & 15.0 & 17.5 & 20.0 & 22.5 & 25.0 & 27.5 & 30.0\end{array}$
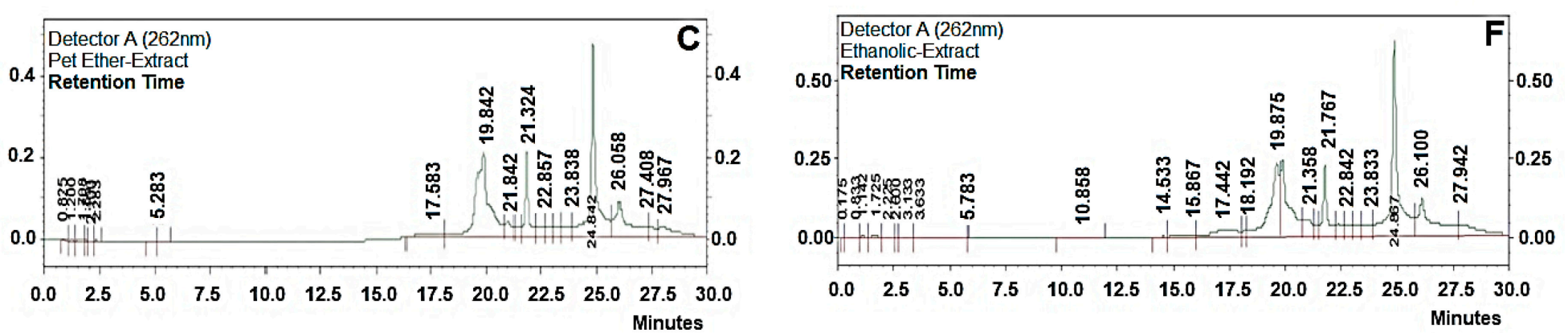

Figure 2. High-performance liquid chromatography HPLC chromatograms of bakuchiol (BKL) (A) standard BKL, (B) DCM extract, (C) petroleum ether, (D) acetone (E) methanolic, and (F) ethanolic extract. 

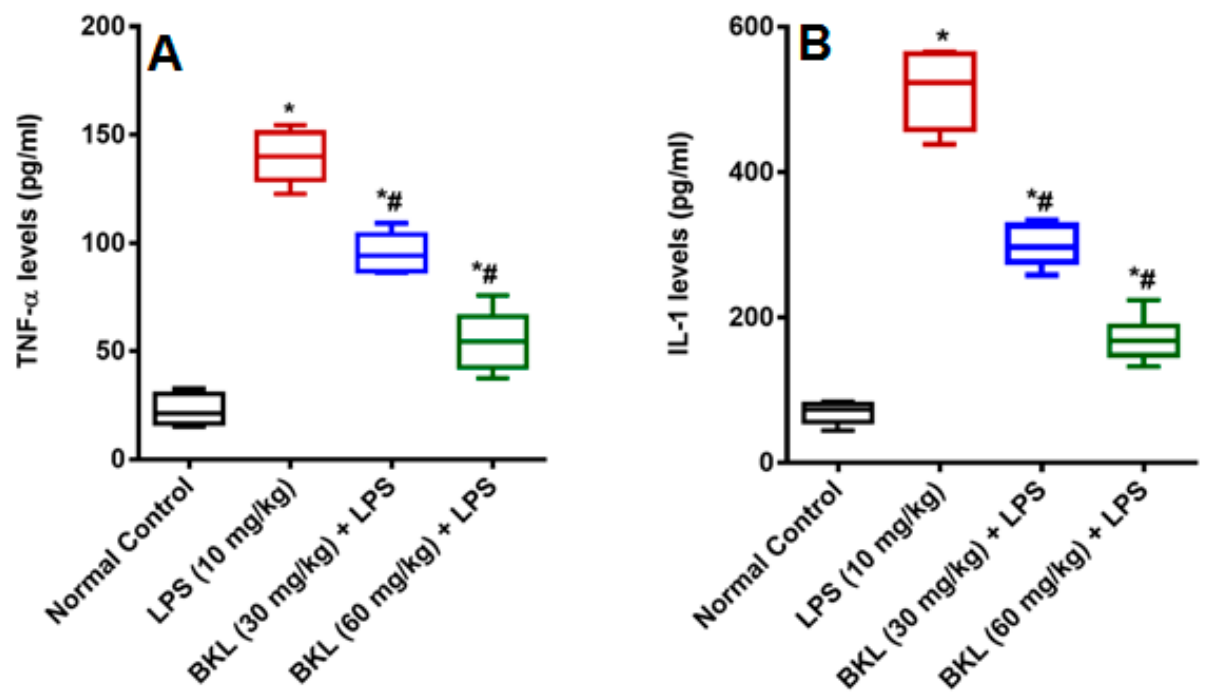

Figure 3. Effect of bakuchiol on LPS-induced proinflammatory cytokines (A) TNF- $\alpha$, and (B) IL-1 $\alpha$ $(\mathrm{pg} / \mathrm{mL})$. Results are represented as mean $\pm \mathrm{SEM}$ of six rats/group. ${ }^{*} p<0.05$ vs. control; ${ }^{\#} p<0.05$ vs. LPS group.

TNF- $\alpha$ and IL-1 in sepsis pathophysiology are perhaps the most widely researched cytokines. They are strong proinflammatory cytokines implicated in a wide variety of inflammatory infectious and non-infectious diseases $[32,33]$. TNF- $\alpha$ is called a chief regulator for the development of inflammatory cytokine, although the essential function of IL-1 in inflammation is well recognized [34,35]. TNF- $\alpha$ and IL-1 act synergistically to induce vascular and pulmonary dysfunctions in a shock-like state [36]. Moreover, TNF- $\alpha$ and IL-1 have also been established as key mediators to a family of pyrogenic cytokines [32,37]. Numerous findings have shown a role for TNF- $\alpha$ and IL-1in sepsis, for both laboratory animal models of septic shock and clinical trials of sepsis $[38,39]$. Bacterial endotoxin administration results in the production and release of TNF- $\alpha$ and IL-1 into the systemic circulation, where peak concentrations are detected from the first 1 to $2 \mathrm{~h}$ of LPS administration [20,40]. BKL is a known antioxidant and in the current study it has been shown that BKL significantly downregulates the inflammatory cytokines, which is in agreement with the previous results of Zhang and co-workers [41]. The results of the current study provide strong evidence that BKL can be recognized as an alternative treatment of pathogen-induced systemic inflammation.

\section{Conclusions}

The percentage yield varied with the solvents and methods of extraction, with the UAE process achieving the highest BKL yield rate followed by Soxhlet method. This difference could be due to the availability of soluble components by different separation methods and solvents. UAE method exhibited the higher extraction content due to its low operated temperatures, which reduces the heat loss caused by high temperatures and also prevents the vaporization during boiling and to preserve the phytoconstituents. Chromatographic analysis showed that BKL percentage was higher in petroleum ether regardless of the extraction methods used suggested that petroleum ether is a favorable solvent for extraction of BKL. In summary, the extraction methods do play a major role for the isolation of BKL from PC (P. coryfolia). This will further help in selecting and optimizing the suitable method of extraction for the herbal compounds. The anti-sepsis potential of BKL indicated that it has a significant inhibitory effect against LPS-induced pathogenic shock by mitigating the circulating levels of biochemical markers (AST, ALT, ALP, BIL, SCr, and BUN) and proinflammatory cytokines (TNF- $\alpha$ and IL-1). Further studies are necessary to explore the clinical implications of such findings. 
Author Contributions: Conceptualization, M.M., S.R.M., and M.A.; methodology, D.K. and S.S.; validation, A.A., M.U.R., and P.A.; formal analysis, D.K., S.S., and A.A.; investigation, M.M., S.S., and M.A.; resources, M.M. and S.R.M.; data curation, M.S.A., M.A., and M.S.E.; writing-original draft preparation, A.A.; and M.U.R.; writing-review and editing, P.A., M.M., and M.S.A.; supervision, M.M. and S.R.M.; project administration, M.M.; funding acquisition, M.S.A. and M.S.E. All authors have read and agreed to the published version of the manuscript.

Funding: The APC was funded by Researchers supporting project number (RSP-2020/173) at King Saud University.

Acknowledgments: The authors are thankful to the School of Pharmaceutical Education and Research, Jamia Hamdard, New Delhi, India, for their support to carry out the work. The authors extend their appreciation to the researchers supporting project number (RSP-2020/173) King Saud University, Riyadh, Saudi Arabia.

Conflicts of Interest: The authors declare no conflict of interest.

Statement of the Novelty: The novelty on this study lies in the recovery of high valuable bioactive compound bakuchiol from $P$. coryfolia Linn using advanced and environmentally-friendly extraction technologies. The obtained extract was found to be having cytokine inhibitory potential against lipopolysaccharides induced systemic inflammation by mitigating the circulating levels of biochemical markers. The feasibility of preparing natural compound will further help in selecting and optimizing the suitable method of extraction for the herbal compounds.

\section{References}

1. Alam, F.; Khan, G.N.; Asad, M. Psoralea corylifolia L: Ethnobotanical, biological, and chemical aspects: A review. Phytother. Res. 2018, 32, 597-615. [CrossRef]

2. Khushboo, P.S.; Jadhav, V.M.; Kadam, V.J.; Sathe, N.S. Psoralea corylifolia Linn.-"Kushtanashini”. Pharmacogn. Rev. 2010, 4, 69-76. [CrossRef] [PubMed]

3. Panda, H. Herbs Cultivation and Medicinal Uses; National Institute of Industrial Re.: Delhi, India, 1999.

4. Zhang, X.; Zhao, W.; Wang, Y.; Lu, J.; Chen, X. The Chemical Constituents and Bioactivities of Psoralea corylifolia Linn.: A Review. Am. J. Chin. Med. 2016, 44, 35-60. [CrossRef] [PubMed]

5. Sah, P.; Agarwal, D.; Garg, S. Isolation and identification of furocoumarins from the seeds of Psoralea corylifolia linn. Indian J. Pharm. Sci. 2006, 68, 768. [CrossRef]

6. Sangeetha, S.; Sarada, D. Psoralea corylifolia linn. (seeds): A Phytochemical Review. J. Pharm. Res. 2012, 5, 1694-1695.

7. Chen, J.; Chen, C.; Lai, R.; Chen, H.; Kuo, W.; Liao, T. New isoflavones and bioactive constituents from the fruits of Psoralea corylifolia. Planta Med. 2011, 77, PG39. [CrossRef]

8. Sun, Y.; Shang, D. Inhibitory Effects of Antimicrobial Peptides on Lipopolysaccharide-Induced Inflammation. Mediat. Inflamm. 2015, 2015, 167572. [CrossRef]

9. Takashiba, S.; van Dyke, T.E.; Amar, S.; Murayama, Y.; Soskolne, A.W.; Shapira, L. Differentiation of monocytes to macrophages primes cells for lipopolysaccharide stimulation via accumulation of cytoplasmic nuclear factor kappaB. Infect. Immun. 1999, 67, 5573-5578. [CrossRef]

10. Borzecka, K.; Plociennikowska, A.; Bjorkelund, H.; Sobota, A.; Kwiatkowska, K. CD14 mediates binding of high doses of LPS but is dispensable for TNF-alpha production. Mediat. Inflamm. 2013, 2013, 824919. [CrossRef]

11. Solomon, K.R.; Kurt-Jones, E.A.; Saladino, R.A.; Stack, A.M.; Dunn, I.F.; Ferretti, M.; Golenbock, D.; Fleisher, G.R.; Finberg, R.W. Heterotrimeric G proteins physically associated with the lipopolysaccharide receptor CD14 modulate both in vivo and in vitro responses to lipopolysaccharide. J. Clin. Investig. 1998, 102, 2019-2027. [CrossRef]

12. Gunt, H. Anti-aging Safely: Bakuchiol for Skin-building Benefits. 2019. Available online: https://www.cosmeticsandtoiletries.com/formulating/category/antiaging/Anti-aging-Safely-Bakuchiol-forSkin-building-Benefits-566575811.html (accessed on 27 August 2020).

13. Park, E.J.; Zhao, Y.Z.; Kim, Y.C.; Sohn, D.H. Protective effect of (S)-bakuchiol from Psoralea corylifolia on rat liver injury in vitro and in vivo. Planta Med. 2005, 71, 508-513. [CrossRef] [PubMed]

14. Cho, H.; Jun, J.Y.; Song, E.K.; Kang, K.H.; Baek, H.Y.; Ko, Y.S.; Kim, Y.C. Bakuchiol: A hepatoprotective compound of Psoralea corylifolia on tacrine-induced cytotoxicity in Hep G2 cells. Planta Med. 2001, 67, 750-751. [CrossRef] [PubMed]

15. Lin, H.C.; Ding, H.Y.; Chang, W.L.; Chao, C.L.; Huang, H.w.; Lin, C.L. Pharmaceutical Composition Containing Bakuchiol for Treating Woman Osteoporosis. U.S. Patent No. 7,714,026, 11 May 2005. 
16. Backhouse, C.N.; Delporte, C.L.; Negrete, R.E.; Erazo, S.; Zuniga, A.; Pinto, A.; Cassels, B.K. Active constituents isolated from Psoralea glandulosa L. with antiinflammatory and antipyretic activities. J. Ethnopharmacol. 2001, 78, 27-31. [PubMed]

17. Haraguchi, H.; Inoue, J.; Tamura, Y.; Mizutani, K. Inhibition of mitochondrial lipid peroxidation by Bakuchiol, a meroterpene from Psoralea corylifolia. Planta Med. 2000, 66, 569-571. [CrossRef] [PubMed]

18. Ahmad, A.; Alkharfy, K.M.; Wani, T.A.; Raish, M. Application of Box-Behnken design for ultrasonic-assisted extraction of polysaccharides from Paeonia emodi. Int. J. Biol. Macromol. 2015, 72, 990-997. [CrossRef]

19. Ahmad, A.; Rehman, M.U.; Wali, A.F.; El-Serehy, H.A.; Al-Misned, F.A.; Maodaa, S.N.; Aljawdah, H.M.; Mir, T.M.; Ahmad, P. Box-Behnken Response Surface Design of Polysaccharide Extraction from Rhododendron arboreum and the Evaluation of Its Antioxidant Potential. Molecules 2020, 25, 3835. [CrossRef] [PubMed]

20. Virzi, G.M.; Clementi, A.; Brocca, A.; Ronco, C. Endotoxin Effects on Cardiac and Renal Functions and Cardiorenal Syndromes. Blood Purif. 2017, 44, 314-326. [CrossRef]

21. Kaur, G.; Tirkey, N.; Chopra, K. Beneficial effect of hesperidin on lipopolysaccharide-induced hepatotoxicity. Toxicology 2006, 226, 152-160. [CrossRef]

22. Kang, Y.J.; Koo, E.B.; Lee, Y.S.; Yun-Choi, H.S.; Chang, K.C. Prevention of the expression of inducible nitric oxide synthase by a novel positive inotropic agent, YS 49, in rat vascular smooth muscle and RAW 264.7 macrophages. Br. J. Pharmacol. 1999, 128, 357-364. [CrossRef]

23. McInnes, I.B.; Leung, B.P.; Field, M.; Wei, X.Q.; Huang, F.P.; Sturrock, R.D.; Kinninmonth, A.; Weidner, J.; Mumford, R.; Liew, F.Y. Production of nitric oxide in the synovial membrane of rheumatoid and osteoarthritis patients. J. Exp. Med. 1996, 184, 1519-1524. [CrossRef]

24. Pacher, P.; Beckman, J.S.; Liaudet, L. Nitric oxide and peroxynitrite in health and disease. Physiol. Rev. 2007, 87, 315-424. [CrossRef] [PubMed]

25. Alkharfy, K.M.; Ahmad, A.; Jan, B.L.; Raish, M. Thymoquinone reduces mortality and suppresses early acute inflammatory markers of sepsis in a mouse model. Biomed. Pharmacother. 2018, 98, 801-805. [CrossRef]

26. Singer, M.; Deutschman, C.S.; Seymour, C.W.; Shankar-Hari, M.; Annane, D.; Bauer, M.; Bellomo, R.; Bernard, G.R.; Chiche, J.D.; Coopersmith, C.M.; et al. The Third International Consensus Definitions for Sepsis and Septic Shock (Sepsis-3). JAMA 2016, 315, 801-810. [CrossRef] [PubMed]

27. Rudd, K.E.; Kissoon, N.; Limmathurotsakul, D.; Bory, S.; Mutahunga, B.; Seymour, C.W.; Angus, D.C.; West, T.E. The global burden of sepsis: Barriers and potential solutions. Crit. Care 2018, 22, 232. [CrossRef] [PubMed]

28. Dombrovskiy, V.Y.; Martin, A.A.; Sunderram, J.; Paz, H.L. Rapid increase in hospitalization and mortality rates for severe sepsis in the United States: A trend analysis from 1993 to 2003. Crit. Care Med. 2007, 35, 1244-1250. [CrossRef] [PubMed]

29. Cohen, J. The immunopathogenesis of sepsis. Nature 2002, 420, 885-891. [CrossRef]

30. Schulte, W.; Bernhagen, J.; Bucala, R. Cytokines in sepsis: Potent immunoregulators and potential therapeutic targets-An updated view. Mediat. Inflamm. 2013, 2013, 165974. [CrossRef]

31. Hansen, J.D.; Vojtech, L.N.; Laing, K.J. Sensing disease and danger: A survey of vertebrate PRRs and their origins. Dev. Comp. Immunol. 2011, 35, 886-897. [CrossRef]

32. Dinarello, C.; Arend, W.; Sims, J.; Smith, D.; Blumberg, H.; O’Neill, L.; Goldbach-Mansky, R.; Pizarro, T.; Hoffman, H.; Bufler, P.; et al. IL-1 family nomenclature. Nat. Immunol. 2010, 11, 973. [CrossRef]

33. Kany, S.; Vollrath, J.T.; Relja, B. Cytokines in Inflammatory Disease. Int. J. Mol. Sci. 2019, 20, 6008. [CrossRef]

34. Parameswaran, N.; Patial, S. Tumor necrosis factor-alpha signaling in macrophages. Crit. Rev. Eukaryot Gene Expr. 2010, 20, 87-103. [CrossRef] [PubMed]

35. Malik, A.; Kanneganti, T.D. Function and regulation of IL-1alpha in inflammatory diseases and cancer. Immunol. Rev. 2018, 281, 124-137. [CrossRef] [PubMed]

36. Okusawa, S.; Gelfand, J.A.; Ikejima, T.; Connolly, R.J.; Dinarello, C.A. Interleukin 1 induces a shock-like state in rabbits. Synergism with tumor necrosis factor and the effect of cyclooxygenase inhibition. J. Clin. Investig. 1988, 81, 1162-1172. [CrossRef] [PubMed]

37. Dinarello, C.A. Overview of the IL-1 family in innate inflammation and acquired immunity. Immunol. Rev. 2018, 281, 8-27. [CrossRef]

38. DHesse, G.; Tracey, K.J.; Fong, Y.; Manogue, K.R.; Palladino, M.A., Jr.; Cerami, A.; Shires, G.T.; Lowry, S.F. Cytokine appearance in human endotoxemia and primate bacteremia. Surg. Gynecol. Obstet. 1988, 166, 147-153. 
39. Lewis, A.J.; Seymour, C.W.; Rosengart, M.R. Current Murine Models of Sepsis. Surg. Infect. 2016, 17, $385-393$. [CrossRef]

40. Suffredini, A.F.; Fromm, R.E.; Parker, M.M.; Brenner, M.; Kovacs, J.A.; Wesley, R.A.; Parrillo, J.E. The cardiovascular response of normal humans to the administration of endotoxin. N. Engl. J. Med. 1989, 321, 280-287. [CrossRef]

41. Zhang, X.; Chang, N.; Zhang, Y.; Ye, M.; Han, Z.; Li, J.; Zhang, J. Bakuchiol Protects Against Acute Lung Injury in Septic Mice. Inflammation 2017, 40, 351-359. [CrossRef]

C 2020 by the authors. Licensee MDPI, Basel, Switzerland. This article is an open access article distributed under the terms and conditions of the Creative Commons Attribution (CC BY) license (http://creativecommons.org/licenses/by/4.0/). 